\title{
Ne Gelmesini Bekliyorsun? (O Çoktan Geldi)
}

Arş. Gör. Ayfer Karabıyık

Makale Geliş Tarihi: 15.04.2015

Yayına Kabul Tarihi: 17.06.2016

\section{Öz}

$\mathrm{Bu}$ metinde, William Kentridge'in 'What Will Come' isimli çalışmasının göstergeleri üzerinden bir yapıt okuması yapılması amaçlanmaktadır. Bu çalışmada, bahsi geçen yapıtın obje olarak ontololjisi ve yapıta ismini veren Gana atasözü arasındaki kaotik ilişkinin peşine düşülür. William Kentridge, bu yapıtıyla-aracı araçsallaştırarak- açığa çıkardığı çok katmanlı anlatı ile önceden olmuş olanın şimdiki görüntüsünü neden-sonuç ilişkileri kurarak izleyiciye gösterir.

Anahtar Kelimeler: Wiliam Kentridge, Anamorfik Film, Kömür Kalem, Çelik Masa, Yansitma

WHAT WILL COME (HAS ALREADY COME)

\begin{abstract}
In this text, to make semiotic analysis is intended to be read through of William Kentridge's art work named as "What Will Come". In this study, is interested inchaotic relationship between the object's ontology of 'What Will Come' and Ghana proverb which is also the name of the art work. To the work, William Kentridge is shows to the viewer which he revealed establishing with cause-and-effect relationships multi-layered narrative that have come before the current image by instrumentalization to tool.
\end{abstract}

Keywords: Wiliam Kentridge, Anamorphic Film, Charcoal, Steel Table, Projection 


\section{Ne Gelmesini Bekliyorsun? (O Çoktan Geldi)}

William Kentridge'in 2007 tarihli solo sergisinin ismi olan "What will come (has already come)" (ne bekliyorsun? O çoktan geldi) bir Gana atasözüdür. "What Will Come" aynı zamanda serginin ana işi olan bu anamorfik film, kökeni 18. Yüzyıl'a dayanan 'Puzzle Resim' fikrinden esinlendiği söylenilebilir. Fakat bu kadarla kalmaz; erken modern çağdan beri modern bilim, popüler kültür ve sanatı da ilgilendiren görme biçimleri üzerine odaklanır. Kentridge, bu çalışmasında, uçuşan çarpık görüntüleri sadece belirli bir açıdan bakıldığında anlaşılabilecek bir algı alanı açar. Fakat izleyicinin görüntüyü okuyabilmesi için bakış noktasını değiştirmesi yetersizdir; aynı zamanda biçimleri açığa çıkartmak için adeta bir dekoder görevi gören özel bir araç gerekmektedir. Kentridge, bu iş için daire biçimli çelik bir masayı görevlendirir. Bu çelik masanın tam merkezine dikine silindirik çelik bir ayna yerleştirir. Bu silindirik ayna masa üzerine bir projeksiyonla yansıtılan amorf biçimleri okur ve izleyiciye gösterir.

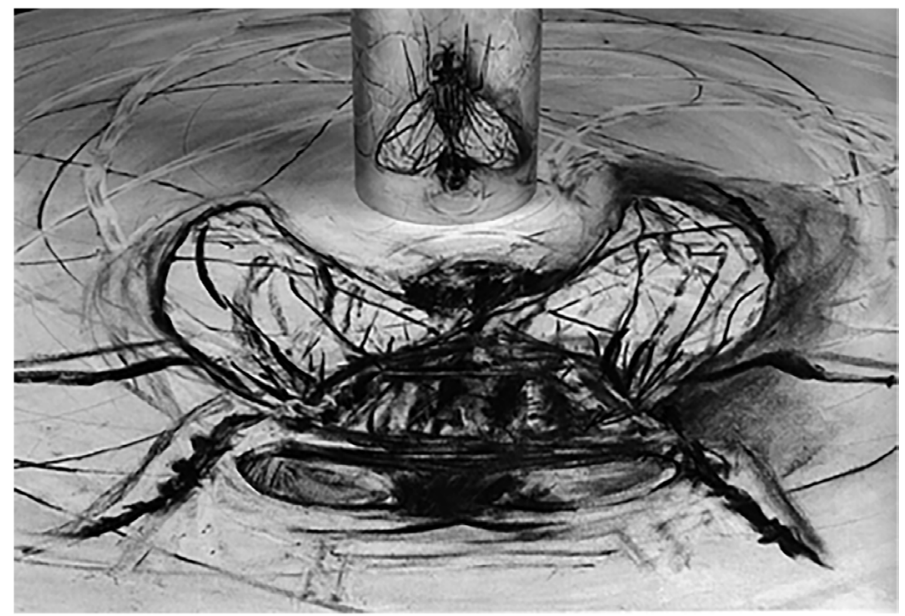

Resim I. William Kentridge, What Will Come (Has Already Come), 2007, Çelik Masa,

Silindirik Çelik Ayna, 35mm Animasyon Film, 8:40 dakika, 4I I/4 x 48 X 48

Tabiki Kentridge bu sunma biçimiyle, izleyiciye, sadece algısal düzeyde bir optik oyun alanı sunmak niyetinde değildir. Aynı zamanda görsel algılama üzerine bir söylem başlatmak ister. "What will come. (Has already come)", estetik yaklaşım biçimiyle, çarpık görüntüleriyle ve -adeta destansı bir meydan okuma sesiyle, izleyiciyi derinden etkileyen bir enstelasyondur. Bu destansı anlatıyı görüntü ve sesle kurgulayarak filmin içine serpiştirir. Politik mesajını derin bir kederle izleyiciye ileten bu heykelimsi aracın kendisi de bu simgesel anlatıya dahil olur. Hatta ontolojik varlığıyla tam da bu 
anlatının merkezine yerleşir.

Karartılmış alanlar, üzeri kağıtla kaplanmış masa, masanın merkezine dikine yerleştirilmiş ayna işlevi gören çelik bir silindir; bu silindir, kağıdın üzerindeki çizimleri ters çevirip yansıtan anamorfik bir lens görevi görür. Kentridge'in çizerek ve silerek oluşturduğu, birbiri ardına kaydedilen imajlarla kurulmuş bu filmik anlatı, kağıdın üzerine yansıtılır. Amorf form ve sahneler içeren çizimler okunur olduğunda, Kentridge'in kolonyalizm, faşizm, ve sömürgecilik meseleleri üzerine odaklandığıaçığa çıkar. Ve bunu tam da sömürgeciliğin aygıtlarıyla gösterir; çelik, kömür, ve teknik araçlar... W. Kentridge, bir bakıma Modernizmin güncel tanıklığını yapar, Afrika coğrafyasından faydalanmaya gelenlerin bu coğrafyada yapıp ettiklerini yine onların aygıtlarını kullanarak gösterir." 1930'lardaki Italya-Etyopya savaşı hakkında olan bu anomorfik film, yansıtma prensibiyle çalışır; çarpıklık ters çevrilerek düzeltilmiştir, özgün olansa çarpıktır ${ }^{1 " .}$

Çalışmada, Afrika coğrafyasına ait formlar seçilmiştir; ağaçlar, bir kuş, büyük bir sinek, bir gergedan, bir silah. İtalyan birliklerinin istilasını işaret eden bir gaz maskesi. Her şey aniden adeta bir üfleme ile birlikte patlar;

Film, Ocak-1935 yılında 'Abyssinia' olarak da bilinen, İtalya'nın Etiyopya'ya yaptığı saldırıyı konu edinir. Etiyopyalıların beklenmedik büyük direnişi Mayıs 1936'ya kadar sürdü. 275,000 Etiyopyalı öldürüldü. Adolf Hitler, Berlin-Roma aksisinin güvenliğinin sürekliliği için gerekli gördüğü enerji kaynakları olan çelik ve kömürü elde etmek adına, İtalyan diktatör Benito Mussolini'yi desteklemiştir. Kentridge'in bu çalışmasında, savaşın sonuçlarından dolayı ortaya çıkan büyük kıtlık nedeniyle Etiyopya Yahudilerinin 1984 yılında İsrail'e göç etmelerini de anlatan bir kompozisyon vardır. Burada Kentridge'in açığa çıkardığı şey çok daha kapsamlıdır. Sadece bir savaş anı anlatısı olmaktan ziyade; 19. Yüzyıl sonlarında italya'nın bu topraklarda kurduğu kolonileri de anlatır. Aynı zamanda Kolonyalizmi Faşizm arasındaki bağı ve günümüze kadar tarihle olan bağını da açığa çıkartır. Bu bağ, Kentridge'in diğer çalışmalarında da vurguladığı, doğup büyüdüğü Güney Afrika'daki Apartheid'in tarihsel durumuyla tutarlılık gösterir. İtalya 1995'e kadar Etiyopya direnişi süresince kimyasal gaz kullandığını reddetmiştir (Gross, 2009: 93-95).

\footnotetext{
I T.William Kentridge, Featured in ART2 I, PBS, Art in the Twenty-First Century, Season 5 (2009), Compassion.

http://www.art2l.org/films/art-in-the-twenty-first-century-season-5-2009
} 


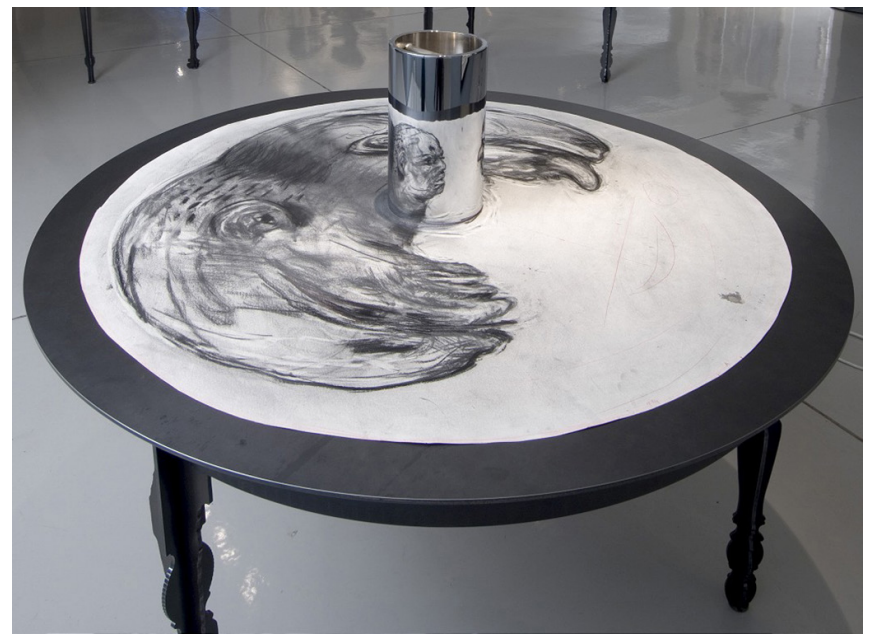

Resim 2. William Kentridge, What Will Come (Has Already Come), 2007, Çelik Masa, Silindirik Çelik Ayna, 35mm. Animasyon Film, 8:40 dakika, 4I I/4 x 48 x 48

Kentridge, Black Box isimli çalışmasında da benzer bir yaklaşımla Mozart'ın Sihirli Flüt (The Magic Flute) eserinin uyarlamasını yapmıştır. Mozart'ın yaşadığı 18. Yüzyıl, 1789 Fransız Devrimiyle zirveye ulaşan Aydınlanma Felsefesi'nin sonuçlarını göstermeye başladığı bir dönemdir. Sihirli Flüt, Aydınlanma Felsefesi'nin, Sahne Sanatları'ndaki en başarılı temsillerinden biri sayılır. Sihirli Flüt, Christoph Martin Wieland'ın Masal Koleksiyonu isimli kitabında yer alan "Lulu, or the Magic Flute" isimli masala dayanır. Kentridge, orijinal teması Aydınlanma Felsefesi olan bu operayı yeniden yorumlar.

Black Box, Kentridge'in Magiç Flute'ün tartışmaya açık aydınlanma hareketine tepki olarak mini-tiyatro mantığında 13 kısa oyundan oluşan bir anlatıdır. Black Box, hakkında çok az şey bilinen bir olayın; 20. yüzyılın başlarında Güney Batı Afrika'da (Nambia) yaşayan yerel halk Herero'ların topraklarını ve emeklerini sömüren Alman kolonyalistlere karşı yapılan isyanı gösterir. Alman güçleri tarafından susuzluk ve açlığa maruz bırakılan Herero Nüfusu bu dönemde \% 75 oranında azalır (MacKenny, 2008: 82-85).

Geçen iki yüz yılda, üç boyutlulukta sağlanan istikrar ve ikna edici bir dünya imajı sunan teknolojiler nedeniyle gizemli anamorfik bilmeceler gözden düşmüştür. Fakat geç kapitalizmin post-realist dönemi ile birlikte anamorfizim, neyin merkezde neyin periferik olduğu hakkındaki hegemonik varsayımları sorgulatan bir enstrüman olarak yeniden değer kazanır. Anamorfizm görünmeyeni gösteren bilinmeyeni bildiren jestüel bir figür olarak yeniden ortaya çıkar. Bilginin buyruğu sezginin buyruğu 
tarafından ironik bir biçimde eleştirilir.

Kentridge'in anamorfik görüntüleri Holbein'in 1533 tarihli, Elçiler (The Ambassadors) isimli resmindeki enigmatik anamorfik kafatası gibidir. Elçiler, Rönesans dönemine aittir. Ait olduğu dönemin Avrupa'sının dünyayı algılama fikrini göstermesi bakımından önemlidir.
Holbein'in bu resmi Batı görme geleneği içinde anamorfik sanatın başat örneği olarak yerini almıştır. Fakat onun otoritesi yalnızca formel anamorfik özelliklerini çoktan aşmıştır. Belkide burada (Slavoj Zizek'in ünlü formülasyonuyla) 'yamuk bakmak' pratiği ve "The Ambassadors" arasında ilişki kurmak kaçınılmazdır. Elçiler politik başarının birer simgesi olarak orada dururlar; onlar bir anlamda Machiavelli'nin ajanlarıdırlar. Bizim modernitemiz tam da bunun üzerine kurulmuştur. Holbein'in "The Ambassadors" ile duble-söylem duble-vizyon söyleminin figür olarak form bulmuş halidir. $^{2}$

John Berger'e göre en ileri uygarlığın Avrupa uygarlığı olduğu düşüncesi aynı zamanda Avrupa'yı merkeze yerleştirir ve diğer uygarlıklar üzerinde tahakküm kurabilmek için yeterli sebep olarak görülür.

Bir ülkeyi sömürgeleştirebilmek için insanlarını Hıristiyan yapmak, onlara hesap öğretmek gerekiyordu: Böylece onlara dünyada en ileri uygarlığın Avrupa uygarlığı olduğu kanıtlanıyordu. Elbette Avrupa sanatı bunun dışında değildi. Burada bizi ilgilendiren onların dünyaya karşı takındıkları tutumdur. Bu da bir sınıfın genel tutumudur. İki elçi dünyanın kendilerine hizmet etmek için var olduğuna inanan bir sınıfın insanlarıdır. En aşırı biçimiyle bu inanç sömürgecilerle sömürgeleştirilenler arasındaki ilişkileri haklı göstermeye yaramıştır. Bu eski bir Ingiliz ilkesidir: "Might is right" (güçlü olan haklıdır). Elçilerdeki güçlü olanın tepeden bakışıdır. Sağdaki elçinin neredeyse gölgesi gibi döşemeye düşen ve yamuk bir bakış ile görülebilen kafatası ise elçinin sorumluluk bölgesindeki sömürgeleştirme işlerinin hızla devam ettiğinin de bir yansımasıdır (Berger, 1999: 88).

\footnotetext{
${ }^{2}$ https://www.academia.edu/22I399I/_Spherical_and_Without_Exits_Thoughts_on_Kentridges_anamorphic_Film_in_Art_in_Australia
} 


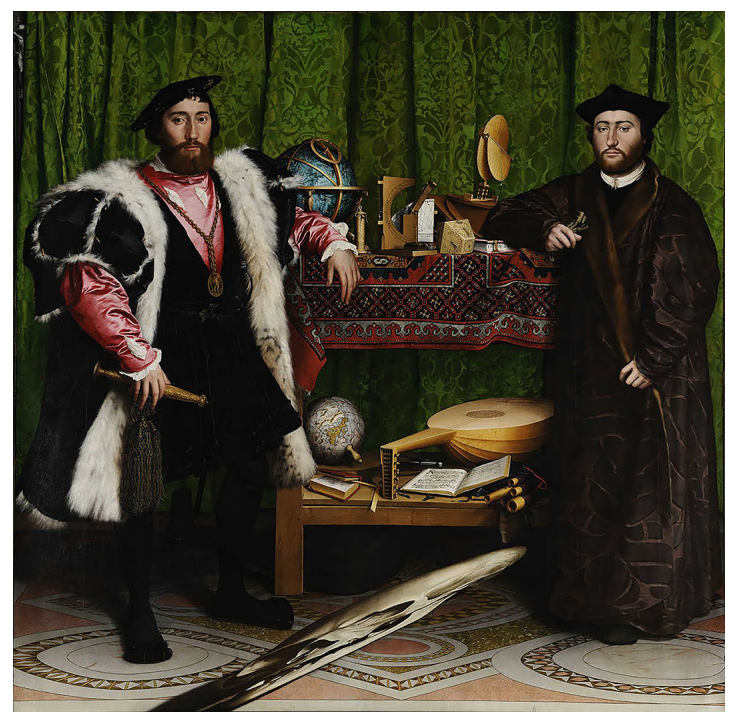

Resim 3. Hans Holbein, The Ambassadors, I533, T.Ü.Y.B 2,07 m x 2, I m

Kentridge, bize görmenin işleyişini ve dünyayı bakarak onu nasıl kurduğumuzu bize fark ettiren makinalarla da ilgilenir. Fakat daha çok bizim dünyayı nasıl algıladığımızla ilgili uçsuz bucaksız metaforlarla ilgilidir. Kentridge görünenle kurduğumuz ilişkilere odaklanır. Aslında sanki bizi uyarmak ister. Şeyleri görmek ve olayları yorumlamak olayların neresinde durduğumuza, görüntüyü nasıl gördüğümüze bağlıdır.

Burada bir parantez açıp Modernizm'in teknik ile olan ilişkisinden bahsetmek gerekir. Böylece Kentridge'in makinalarla kurduğu ilişkiyi de yorumlayabiliriz. Bilim, teknoloji ve toplum ile ilgili araştırmalara baktığımızda yalnızca şeylerin doğasını ve bilgisini değil ekonomik, siyasi ve kültürel her türlü şeye temas eden iktidarın arzu ve inançlarıyla karşılaşırız. Dolayısıyla bilim ve tekniği salt kendi özerklikleriyle değil siyaset üreten aygitlar olarak değerlendirmek gerekir.

Burada bilim ve tekniği Modernizm ile ilişkilendirilerek değerlendirilmesinin sebeplerinden kısaca söz etmek gerekirse; bilim ve siyaset üretme biçimi ile örgütlenme yapısının Avrupa modernitesinden kaynaklanan bilgiiktidara dayanması ve bilime ve siyasete atfedilmiş işlevlerin günümüzde hâlâ hâkim algıyı oluşturmasıdır. Bilim, toplum, ekonomi ve siyasetin hem bugüne kadar birbirinden bağımsız kapalı alanlar olarak varsayılmış salt varlıkları, hem de birbirinin içine çoğu zaman örtük biçimde nüfuz etmeleri söz konusudur. Bu durum, toplumsal bağlamla ve iktidarın değişen arzu ve inançlarıyla doğrudan ilişkilidir. 
Yazının bundan sonraki bölümü işte bu eksende ilerleyerek modern bilim ve modern siyasetin temellerinin atıldığı 17. yüzyıla ve "bir hava pompası" isimli deneysel çalışmaya odaklanacak; böylece hem bilim ve siyaset arasındaki bağın ortaya çıkışı hem de bu deneysel çalışma yapısal olarak Kentridge'in teknik ve mekanik bilgi ile olan ilişkisine referans olarak sunulacaktır.

\begin{abstract}
Mekanik felsefenin etkin olduğu dönemin koşulları ekseninde, özellikle Thomas Hobbes ve Robert Boyle'un (1627- 1691) çalışmaları doğrultusunda, toplumsal yapı ile doğa olayları arasında kurulan analoji, bunun en açık örneğidir. Gözlem ve deneye dayanarak, hakikati keşfetmeye çalsşan Boyle'un, hava pompası ile yaptığı deneye göre; gözle görülemeyen, ancak her yerde var olan bir boşluk olarak beliren hava, yaşamı sürdürmek için tabi olunan mutlak bir gücün varlı̆ı̆nı ve iktidarını kanıtlamaktadır. Hava üzerine yaptığı deneysel çalışmalar ile Boyle, siyasal açıdan, belirli bir aşkın gücün varlığına ilişkin bilginin otoritesine, evrensel bir şekilde rıza gösterilmesini sağlayan hakikatin özünü bulmaya yönelmiştir. Boyle açııından hakikatin bilinebilmesi, ancak birçok insanın, buna tanıklık etmesi ve bu konudaki deneyimlerini paylaşması ile olanakııır. Boyle'un havasız bir fanus içine koyduğu kuşun, tanıkların gözü önünde çırpınarak ölmesi, tanıklara, hakikatin nasıl oluştuğunun anlaşılması yönünde bir deneyim yaşatır. Buna benzer tanıklıklar çoğaldıkça, kanaat ve inançların, bilimsel bilgiye dönüşmesi sağlanır (Özsoy, 2014: 22).
\end{abstract}

Robert Boyle, Devlet'in temelleri yeniden inşa edilirken modern bilimin kurucularından sayılacaktır. Boyle'un çalışma sürecini buradaki tartışma bağlamında değerlendirdiğimizde onun bilgi üretimi sürecinde teknik bilgi ile kanı oluşturma yöntemini nasıl inşa ettiği önem kazanır. İçsel teknoloji yaklaşımı Nelson ve Winter tarafından da ele alınmış, ekonomik kalkınma için teknolojik değişim talep faktörleriçerçevesinde ifade edilmiştir. Modelde yenilikçi işletmeler heterojenliğin sağladığı rekabet için yeni rutinler (bilgi kodları) geliştirmekte, takipçiler rant için başarılı rutinleri kopyalayarak transfer etmektedir (Nelson ve Winter, 1982). Bilgi asimetrik olduğundan işletmeler rekabet halindedir ve teknoloji kolayca ulaşılabilen bir faktör olmaktan çıkmıştır. Teknoloji, üretilmesi için çaba ve kurumsal altyapı gerektiren ve rekabetçi üstünlükler kazandıran bir faktöre dönüşmüştür.

Hakikatin ne olduğu, o güne kadar kanıya ve tanıklığa dayanarak oluşturuluyordu. Ancak Boyle gözleme, deneye ve kanıta dayanarak matter of fact'i, yani gerçeği ve hakikati oluşturan şeyi keşfetmeye çabalamıştır. İnsanların kanısı ve tanıklığının bilgiyi ve hakikatin içeriğini etkileyebilme iktidarına karşı Boyle, şeylerin tanıklığını önerir. Şeylerin tanıklığına dayanarak hakikatin bilgi ve bilim olarak değerlendirilmesinin temelleri, Boyle'un hava pompası ile yaptığı deneyde bulunur. Boyle'un ilk dönem 
çalışmalarına baktığımızda yaptığı gözlemlerin ve edindiği deneyimlerin ezoterik sayılabilecek bir şekilde kaydının tuttuğunu görürüz. Gündelik hayatın içinde eğitim, cins-kimlik, statü ve meslek açısından farklı düzeydeki insanların doğa ile kurdukları ilişkide nasıl kanı geliştirdiklerini inceler. Bu, onun aynı zamanda bilginin ve iktidarın oluşturulma süreci ile ilgilendiğini de bize gösterir. ${ }^{3}$

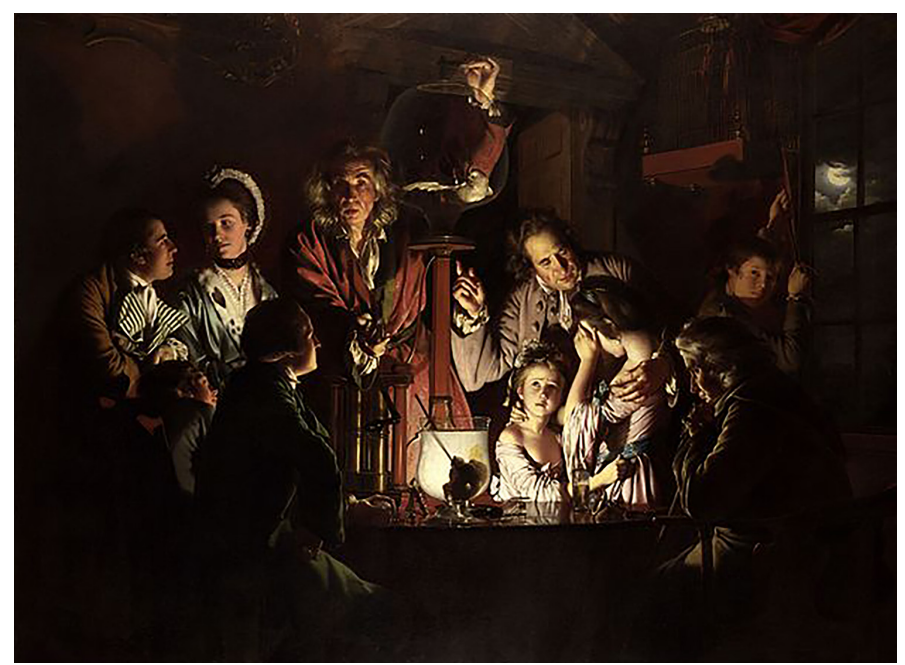

Resim 4. Joseph Wright of Derby, An Experiment on a Bird in the Air Pump, I 768, T.Ü.Y.B, $183 \mathrm{~cm} \times 244 \mathrm{~cm}$

Bilim, teknoloji ve toplum ile ilgili araştırmalara baktığımızda yalnızca şeylerin doğasını ve bilgisini değil ekonomik, siyasi ve kültürel her türlü şeyle ilişkide olan iktidarın arzu ve inançlarıyla karşılaşırız. Bu yüzden şeyleri yakından incelemek ve hayata miyop bakmak, bugün yukarıdan bakan genellemeci ve indirgemeci makro bakış açısına göre bambaşka sonuçlar doğurabilir. Böylelikle iktidarın arzu ve inançlarının, ekonomik, siyasi ve kültürel her türlü kolektifte nasıl meydana geldiğini ve işlediğini açı̆̆a çıkarabilmiş oluruz. Artık birbirinden farklı alanlar olarak değerlendirilenler arasındaki ilişkilerin kartezyen ve yapısalcı ikili karşıtlıkları aşarak yeniden okunması ve bu tahakküm eden temsil anlayışının yapıbozuma uğratılması yoluyla toplumsal bağlamın ve iktidarın arzu ve inançlarının da bir başka şekilde okunabilmesinin mümkün olduğunu görürüz.

\footnotetext{
${ }^{3}$ Yetişkin, E. (20I I). Bir Hava Pompası ile Devlet arasında Nasıl Bir İlişki Olabilir? Bilim, Siyaset ve Sömürgecilik.https://www.academia.edu/3037300/Bilim_Siyaset_ve_S\%C3\%B6m\%C3\%BCrgecilik_Bir_Hava_Pompas\%C4\%BI_\%C4\%BOle_Devlet_Aras\% $\overline{\%} \overline{4} \% \mathrm{BI}$ Inda_Nas\%C4\%BII_Bir_\%C4\%B0li\%C5\%9Fki_Var
} 
Örneğin "The Pasteurization of France" başlıklı bir siyasi-biyografik araştırma yapmış olan Bruno Latour (1984) çalışmasında Louis Pasteur'un mikropları evcilleştirmesini betimleyerek yaklaşık yüz yıl önce özgürlük, eşitlik ve kardeşlik ilkeleri etrafında Fransız Devrimi'ni gerçekleştirmiş 19. yy. Fransa'sında mikrop bulaşmış garibanların durumunu incelemiş, böylelikle sosyo-ekonomik ve siyasi toplumsal bağlam ile iktidarın arzu ve inançlarındaki değişimi yeniden değerlendirmiştir. Kurtarıcı gözüyle bakılan pozitivist bilimin ve bilimcinin yüceltilmesi, aynı zamanda mikropların /ya da mikrop olarak değerlendirilenlerin evcilleştirilmesi yani pastörizasyonu yoluyla ulusdevletin kalkınmasına da katkıda bulunacaktır. Bugün bilim ve siyasete atfedilmiş olan bu yüceleştirme yaklaşımını çağdaş sanatta da görmek mümkün. ${ }^{4}$

Kentridge'in performatif denilebilecek bu çalışması, teknik bir aygıt aracılığıyla yeniden üretilmiş olan bir takım olayların gözlemlenebilmesi ve bu olaylar ve imajlar arası ilişkilere tanıklık edilmesini sağlamıştır. Kentridge bunu birbirinden bağımsı gibi görünen parçaları bir araya getirerek, onları yeniden fragmanlar halinde sunarak yapar. Parça-bütün diyalektiğine dayanan bakış ve parçaların oluşturduğu bütün modernitenin bakış açısını da bize gösterir. Bu noktada bir hususu vurgulamakta belki de yarar vardır. Modernite, eski ile yeni arasında kurulan süreklilik içinde farkı ve değişimi sağlayan kopuşa ve kırılma noktasına vurgu yapar. Aydınlanma ilkelerini temel alan Modernizm akıl, nesnellik, ilerleme, özgürlük, hakikat ilkeleri üzerine inşa edilir. Yenilik, yaratıcılık ve ilerlemenin başat mottolar olmasının bir nedeni de bu hâkim modern zihniyetin benimsenmesindendir. Böylelikle geçmiş, şimdiki zaman ve gelecek arasında kurulan lineer zaman algısının sürekliliği içinde, daha iyi ve daha doğru olacağına inanılan bir gelecek inşa etmek için şimdiki zamanın koşulları ile geçmişe dönülür, sorunlar tespit edilir. Neden-sonuç ilişkileri kurarak bu sorunlara çözüm bularak yasa oluşturmaya yönelik bir şekilde düşünülür, hareket edilir, fark üretilir. İlerleme, gelişme, kalkınma gibi geleceğe dair hedefler, birbirinden bağımsızmış gibi varsayılan ancak birbiriyle tutarlı bir şekilde sanki bir makine gibi işleyen bu modern aklın, kurumların ve pratiklerin ürünüdür. $\mathrm{Bu}$, aynı zamanda bir nesne üzerinden nesnel bilginin, gerçekliği oluşturan mesele ya da madde, yani bir "matter of fact" olarak inşa edilmesidir. Kanıtı oluşturan düzeneğin nasıl çalıştığı son derece önemli bir unsurdur, kanıt yoluyla bir gerçekliğin oluşturulması bilgi-iktidar inşası için yeterli görülebilecektir. Sonuç olarak bugüne kadar birbirinden bağımsız, farklı ve birbirine karşıt olarak tanımlanan ve sınıflandırılanlar arasında

\footnotetext{
${ }^{4}$ Yetişkin, E. (20I I). Bir Hava Pompası ile Devlet arasında Nasıl Bir İlişki Olabilir? Bilim, Siyaset ve Sömürgecilik.https://www.academia.edu/3037300/Bilim_Siyaset_ve_S\%C3\%B6m\%C3\%BCrgecilik_Bir_Hava_Pompas\%C4\%BI_\%C4\%BOle_Devlet_Aras\% $\overline{\%} \overline{4} \%$ BI nda_Nas\%C4\%BII_Bir_\%C $4 \%$ B0li\%C5\%9Fki_Var
} 
kurulan disimetrik ittifaklar, bir araya gelmeler ve dağılmaların dinamik ve paradoksal işleyişine odaklanmak bugün pek de iyi okunamayan sorunları karşımıza seriyor. Bu etkileşim süreci içinde Kentridge'in bu çalışmasındaki düzenek; mekaniğin kendisi, mekanik tekrarlar ile bir araya gelmeler ve dağılmalar, yansıtmalar/yansımalar temsilin bilgiyi nasıl yeniden ürettiği üzerine düşünülebilir. 


\section{Kaynakça}

Berger, J. (1999). Görme Biçimleri (çev. Yurdanur Salman). İstanbul: Metis Yayınları.

MacKenny, V. (2008). William Kentridge, Flute De Arte, 77, 82-85.

Gross, J. R. (2009). William Kentridge's What Will Come. Yale University Art Gallery Bulletin State of the Art: Contemporary Sculpture, 93-95.

Özsoy, S. (2014). "Kütle Çekimive Görünmeyen ElÜzerine Bir Deneme”, Uludağ Üniversitesi Fen-Edebiyat Fakültesi Felsefe Dergisi, 22, 84-85

\section{İnternet Kaynakları}

Featured in ART2I. (2009). Kentridge, W. Featured in ART2I, PBS, Art in the TwentyFirst Century, Season 5 Compassion. http://www.art2 I.org/films/art-in-the-twenty-firstcentury-season-5-2009 adresinden çevrilmiştir.

Taylor, J. Spherical and Without Exits: Thoughts on William Kentridge's anamorphic film What Will Come (Has Already Come). art\& australia. Web: https://www.academia. edu/2213991/_Spherical_and_Without_Exits_Thoughts_on_Kentridges_anamorphic_ Film_in_Art_in_Australia adresinden 01 Ocak 2016 tarihinde alınmıştır.

Yetişkin, E. (20II). Bir Hava Pompası ile Devlet arasında Nasıl Bir Iilişki Olabilir? Bilim, Siyaset ve Sömürgecilik. Web: https://www.academia.edu/3037300/Bilim_Siyaset_ ve_S\%C3\%B6m\%C3\%BCrgecilik_Bir_Hava_Pompas\%C4\%BI_\%C4\%BOle_Devlet_ Aras\%C4\%BInda_Nas\%C4\%BII_Bir_\%C4\%BOli\%C5\%9Fki_Var adresinden 03 Nisan 2016 tarihinde alınmıştır.

\section{Görsel Kaynakları}

Resim I. http://www.silviaminguzzi.com/anotherperspective/kentdrige.htm

Resim 2. http://www.goodman-gallery.com/exhibitions/438

Resim 3. https://en.wikipedia.org/wiki/The_Ambassadors_(Holbein)

Resim 4. https://en.wikipedia.org/wiki/An_Experiment_on_a_Bird_in_the_Air_Pump 